Such an apparatus was exhibited at the last meeting of the Michigan Schoolmasters' Club, and gave as a result $20.8 \mathrm{cc}$. detonating gas and 14.05 water vapor, and many of the results are even better than this.

AN APPARATUS FOR ILLUSTRATING THE EQUALITY OF EXPANSION OF DIFFERENT GASES.*

By C. F. Adams.

Central High School, Detroit.

The apparatus here described is intended to illustrate before a class that different gases expand equally under similar conditions. It consists essentially of two air-thermometers of equal size supported upon a wooden standard as shown in Fig. 1. The bulbs of these thermometers are two small flasks of about $100 \mathrm{cc}$. capacity.

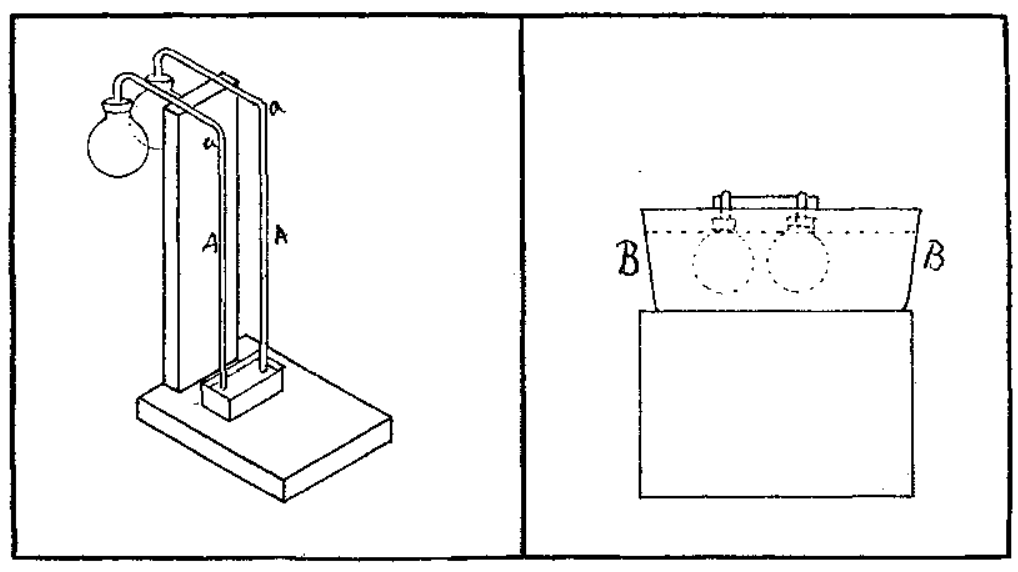

FIG. 1

FIG, 2

The capacities of these flasks were first tested to see that they were equal and marks made upon their necks with a file to show how far the stoppers should be inserted to maintain the equality. About $3 \mathrm{cc}$. of sulphuric acid are placed in each flask to keep the gases dry. The vertical part of the stems of the thermometers, A A, consists of a small slim pipette or burette graduated in tentlis of a cubic centimeter from 0 to $5 \mathrm{cc}$. They were selected so that the lengths of the graduated parts are equal and the zero marks

*Read before the Physical Conference of the Michigan School Masters' Club, April 1, 1905. 


\section{Expansion of Gages}

equally distant from the end. These pipettes, inverted, are connected to the flasks by glass tubing bent as shown in the figure. The union at $a$ a may be made by rubber tubing, but it is an easy matter to fuse the pipettes to the tubing and the apparatus is more permanent and there is less danger of leakage. Care should be taken to have the bottoms of the two flasks at the same level and the lower ends of the pipettes should also be at the same level. These dip into a beaker containing concentrated sulphuric acid. Commercial acid should be used since it can be easily seen in the tubes at a distance.

The flasks are closed by stoppers having two holes. After the apparatus is set up one of the flasks is filled with hydrogen or other gas by inserting a delivery tube of a gas generator in one of the holes of the stopper and gas passed through until all of the air is expelled. The hole in the stopper is then closed with a glass plug. The other flask is filled with air. The chief difficulty in setting up the apparatus is in making it perfectly air-tight.

In using it a large basin of water B B (Fig. 2) is placed upon a box at such a height that when the flasks are placed in it and the wooden support rests on the table, the flasks do not quite touch the bottom of the basin. The support for the thermometers should be heavy enough to hold the flasks down in the water. Before the apparatus is used the flasks should be placed in water about $10^{\circ}$ warmer than will be used in the class room, say about $45^{\circ} \mathrm{C}$. Thus some of the gases will be expelled so that at about $20^{\circ} \mathrm{C}$. the acid will stand near the top of the graduation in the stems of the thermometers. For the actual experiment it is best to have two basins, one containing water at about $20^{\circ} \mathrm{C}$, and the other water at about $35^{\circ} \mathrm{C}$. The flasks can then be placed alternately in one basin and then in the other and the expansion and contraction noted. It will be readily seen that the experiment will take very little time in the class and that it can be repeated with very little trouble. 